\title{
Protective Effect of Zinc (Zn) on the Histology and Histochemistry of Liver and Kidney of Albino Rat Treated with Cadmium
}

\author{
Alsayed Ali Mahran'1, Husam Eldien H. Osman¹, Ahmed M. A. Abd El-Mawla ${ }^{2,3 *}$ and Adel M. Attia ${ }^{4}$ \\ ${ }^{1}$ Department of Anatomy and Histology, Faculty of Medicine and Medical Sciences, Taif University, Taif 21974, Saudi Arabia \\ ${ }^{2}$ Department of Pharmacognosy, Faculty of Pharmacy, Assiut University, Assiut 71526, Egypt \\ ${ }^{3}$ Department of Pharmacognosy, Faculty of Pharmacy, Taif University, Taif 21974, Saudi Arabia \\ ${ }^{4}$ Department of Pharmaceutical Chemistry, Faculty of Pharmacy, Taif University, Taif 21974, Saudi Arabia
}

\begin{abstract}
The protective effect of zinc ( $\mathrm{Zn})$ on the liver and kidney of albino rats exposed to intraperitoneal injection of cadmium chloride $\left(\mathrm{CdCl}_{2}\right)$ was studied. Light microscopic examination for rats which were injected intraperitonealy with of $0.16 \mathrm{mg} \mathrm{CdCl} / 2 \mathrm{~kg}$ of body weight for 8 weeks indicated severe histological changes in both liver and kidney. In liver, a blurred trabecular structure, vacuolar degeneration and increased density of nuclear chromatin with very compact nuclear structure were found in hepatocytes. Moreover; mononuclear cell infiltrations and necrosis of single cells were also observed. In the kidney tubules, degeneration and hypertrophy of epithelial cells and dilation in the glomeruli were also observed. The effects of cadmium on the ultrastructures of both organs were studied. There are ultrastructural damages appeared in both organs as nuclear membrane damage, chromatin condensation, swelling of the mitochondria with regression of mitochondrial cristae, degranulation and disintegration of protein-synthesizing structures such as rough endoplasmic reticulum, increased number of lysosomes and ultimately cell death. Zn partially alleviated the damage observed in both the liver and kidney and differences in histological structure has been observed between the $\mathrm{Zn}-\mathrm{Cd}$ and the control groups. Our results demonstrate the protective effect of $\mathrm{ZnCl}_{2}$ in prevention $\mathrm{CdCl}_{2}$ - induced significant toxic pathological changes in the liver and kidney of the albino rats.
\end{abstract}

Keywords: Zinc chloride; Cadmium chloride; Kidney; Liver; Histology; Histochemistry

\section{Introduction}

Cadmium (Cd) is known as a heavy and high toxic metal that widely distributed in the environment. It is present in trace levels in seawater and a broad range of animal and plant species [1-5]. It was reported that the maximum tolerance dietary $\mathrm{Cd}$ level for domestic animals was $0.5 \mathrm{ppm}$. Dietary concentrations of one ppm Cd results undesirable effects, while concentrations of $5 \mathrm{ppm}$ leads to adverse health effects [6]. Gastrointestinal absorption of $\mathrm{Cd}$ is affected by the diet and nutritional status [7]. Absorption of ingested Cd is only about $5 \%$ and after absorption it accumulates in the liver and then in the kidney [8,9]. Therefore, one of the most important health effects of chronic Cd exposure is the liver and kidney damage $[2,10,11]$.

Zinc is one of the important nutrients that can reduce the toxicity of orally administrated $\mathrm{Cd}$ and shows its effect by competing with $\mathrm{Cd}$ for some transport system as well as for the bending sites in the metalothionin $[2,9,12,13]$. The aim of the present study was to investigate the histological and histochemical changes in the liver and kidney of albino rat exposed to intraperitoneal injection of $\mathrm{Cd}$, and the protective effect of intraperitoneal injection of zinc on Cd-induced changes in both.

\section{Materials and Methods}

\section{Animals}

The present study was based on materials obtained from 60 adult albino rats of both sexes with body weigh from 220-250 gm. The experiment was conducted to 8 weeks, and the animals were randomly designed into three groups, each of 20 rats: two experimental groups and one control group. Each group was isolated in a single cage and kept in the same conventional condition of diet and environment in the animal house.

\section{Chemicals}

The cadmium chloride $\left(\mathrm{CdCl}_{2}\right)$ and zinc chloride $\left(\mathrm{ZnCl}_{2}\right)$ of analytical grade or higher purity were the substances used in this study. Each was soluble in physiological saline and was injected intraperitonealy at dose levels of $0.16 \mathrm{mg} \mathrm{CdCl} / \mathrm{kg}$ of body weight and $0.53 \mathrm{mg} \mathrm{ZnCl} / \mathrm{kg}$ boy weight [9].

\section{Experimental design}

The experiment was conducted for 8 weeks. The animals were randomly allocated into three groups: two experimental groups and one control group each include 20 rats.

Rats of experimental group 1 were injected intraperitonealy with cadmium chloride solution ( $0.16 \mathrm{mg} \mathrm{CdCl}_{2} / \mathrm{kg}$ of body weight) [9].

Rats of experimental group 2 were injected intraperitonealy with both zinc chloride solution ( $0.53 \mathrm{mg} \mathrm{ZnCl}_{2} / \mathrm{kg}$ of body weight) [9] after injection with cadmium chloride in an aforementioned dose.

Rats of control group were received injection of the same dose of normal saline. The injections were done into the peritoneum of used rats for eight weeks five times/week. The animals of each group were

*Corresponding author: Dr. Ahmed Abd El-Mawla, Department of Pharmacognosy, Faculty of Pharmacy, Assiut University, Assiut 71526, Egypt, Tel: +20882411330; Fax:+20882332776; E-mail: Ahmedpha2000@yahoo.com

Received April 30, 2011; Accepted September 10, 2011; Published September 13, 2011

Citation: Mahran AA, Husam Eldien HO, Abd El-Mawla AMA, Attia AM (2011) Protective Effect of Zinc ( $\mathrm{Zn})$ on the Histology and Histochemistry of Liver and Kidney of Albino Rat Treated with Cadmium. J Cytol Histol 2:123. doi:10.4172/21577099.1000123

Copyright: (c) 2011 Mahran AA, et al. This is an open-access article distributed under the terms of the Creative Commons Attribution License, which permits unrestricted use, distribution, and reproduction in any medium, provided the original author and source are credited. 
Citation: Mahran AA, Husam Eldien HO, Abd El-Mawla AMA, Attia AM (2011) Protective Effect of Zinc (Zn) on the Histology and Histochemistry of Liver and Kidney of Albino Rat Treated with Cadmium. J Cytol Histol 2:123. doi:10.4172/2157-7099.1000123

sacrificed with inhalation of over dose of ether. The kidney and liver were excised and divided into small pieces for histological examination.

\section{Light microscopy}

Small slices of kidney and liver tissue were taken and fixed in $10 \%$ formalin for 24 hours, and were imbedded in paraffin. Five-micronthick sections were routinely stained with hematoxyline and eosin [14].

\section{Histochemical study}

Some paraffin sections were stained with (a) periodic acid-Schiff's method to demonstrate carbohydrates [15] and with (b) Mallory method to demonstrate the tissue fibroses [14].

\section{Electron microscopy}

Both liver and kidney were cut into small pieces $1 \mathrm{~mm}$ thick and fixed in ${ }_{4}$, G in phosphate buffer solution ( $\mathrm{pH} \mathrm{7.2)} \mathrm{for} 3 \mathrm{~h}$ at $4^{\circ} \mathrm{C}$, after which the tissues were removed and postfixed in buffered $2 \% \mathrm{OsO}_{4}$ for one hour at $4^{\circ} \mathrm{C}$. Postfixed tissues were rinsed in the buffer and dehydrated at $4^{\circ} \mathrm{C}$ through a graded series of ethanol. Then they were embedded in epon-araldite mixture in labeled beam capsules. Ultrathin sections (50 $\mathrm{nm}$ thick) were cut, collected on naked copper-mesh grids and stained with uranyl acetate for $1 / 2$ hour and lead citrate for 20-30 $\min [16]$.

\section{Results}

\section{Light microscopic observations}

The Liver of a control rat should a normal structure where the liver appeared to de composed of hexagonal or pentagonal lobules with a central veins and peripheral hepatic triads or tetrads embedded in connective tissue. The hepatocytes are arranged in trabecules running radiantly from the central vein and the spaces between the cell cords called blood sinusoids which converged towards the central vein and lined by Kupffer cells. Also the hepatocytes are regular and contain a large spherical nucleus with a distinctly marked nucleolus and peripheral chromatin distribution. Some cells have two nuclei (Figure 1 and 2).

The Kidney of control rats, had normal renal structure of both (a) cortex which showed a normal structure of; renal glomeruli.

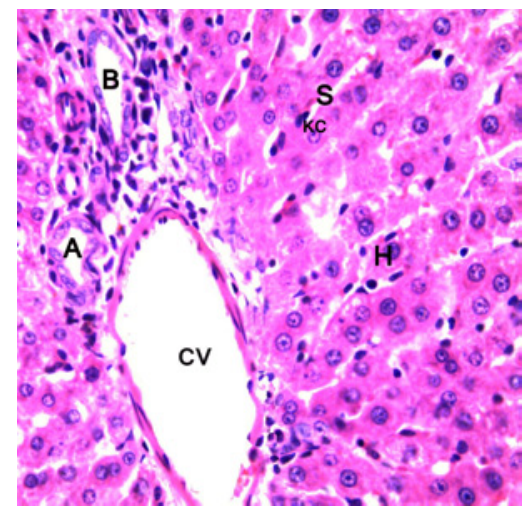

Figure 1: Light photomicrography of liver of a control rat: the organ It is composed of lobules which are roughly hexagonal in shape, with portal triads at the vertices and a central vein (CV) in the middle. Within each lobule, hepatncytes $(\mathrm{H})$ are arranged into hepatic cords running radiantly from the central vein and are separated by adjacent blood sinusoids (S) containing Kupffer cells. N.B; Bile duct (B), Hepatic artery (A). H\&E. x400

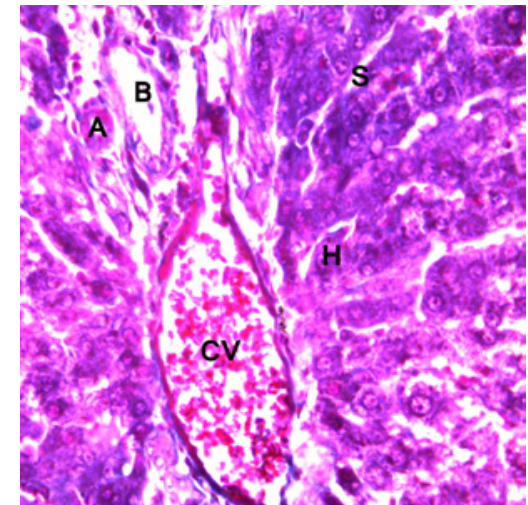

Figure 2: Light photomicrography of liver of a control rat: the organ It is composed of lobules which are roughly hexagonal in shape, with portal triads at the vertices and a central vein (CV) in the middle. Within each lobule, hepatncytes $(\mathrm{H})$ are arranged into hepatic cords running radiantly from [he central vein and are separated by adjacent blood sinusoids (S). N.B: Bile duct (B), Hepatic artery (A). Mallory's x400.

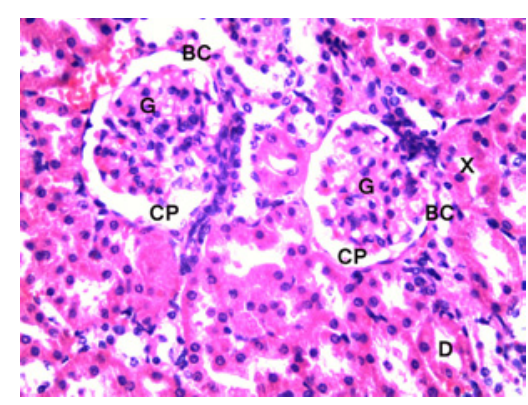

Figure 3: Light photomicrography of Kidney (cortical part) of a control rat. The renal glomeruli $(G)$ show normal structure and the proximal $(X)$ are lined with typical thick cubic epithelium and distal (D) convoluted tubules are lined with the relatively low simple cubic epithelium. Organization of the glomeruli and a flat epithelium lining the glomerular capsule (BC) with distinct capsular space (CP) can be seen. H\&E, $\mathbf{x} 400$.

The proximal convoluted tubules are lined with typical thick cubic epithelium. The distal convoluted tubules show considerably lower cubic epithelium. The tubules have a relatively regular distinct lumen., the glomerular capsule are lined with a flat epithelium, and (b) medulla in which, the collecting tubules are lined with the relatively low simple cubic epithelium. The thick descending and ascending parts of Henle's loops are lined with simple cubical epithelium with small caliber, and a small amount of interstitial tissue can be seen normally in the crosssections (Figure 3 and 4 ).

Light microscopic examination in the liver of rats treated with $\mathrm{CdCl}_{2}$ showed that there were degenerative changes in numerous hepatocytes; the cells were enlarged and had light and foamy cytoplasm filled with numerous vacuole-like spaces. The walls of the blood sinusoids were dilated and showed numerous Kupffer cells. In a few liver zones, the $\mathrm{CdCl}_{2}$ induced also hepatocytes necrotic changes which appeared as; a small, pycnotic cellular nucleus with condensed chromatin, lack of nucleolus and strongly acidophilic cytoplasm. Mononuclear cell infiltrates were also noted in hepatic areas (Figure 5 and 6).

Light microscopic examination in the kidney of rats treated with $\mathrm{CdCl}_{2}$ only showed that there were many areas of tubular damages 
Citation: Mahran AA, Husam Eldien HO, Abd El-Mawla AMA, Attia AM (2011) Protective Effect of Zinc (Zn) on the Histology and Histochemistry of Liver and Kidney of Albino Rat Treated with Cadmium. J Cytol Histol 2:123. doi:10.4172/2157-7099.1000123

ranged from mild to severe in the kidney were observed in all treatment animals. These renal damages appeared as hypertrophy and degeneration of epithelia of renal tubules with distinct of mononuclear cells infiltration. A few renal tubules showed single epithelial cells desquamated to their lumen. Also some vascular glomeruli were apparently enlarged, tightly filling the Bowman's capsule with absence of the capsular spaces was observed. Moreover, hyperaemia of the kidney vessels was observed (Figure 7 and 8).

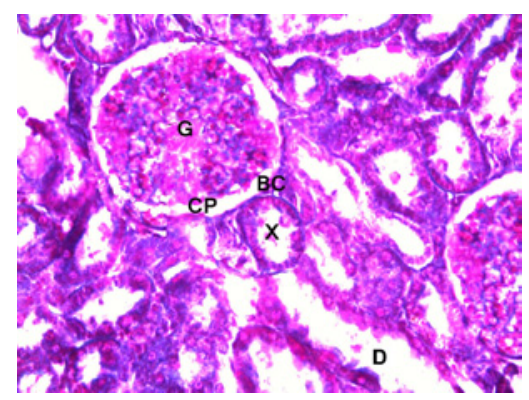

Figure 4: Light photomicrography of Kidney (cortical part) of a control rat . The renal glomeruli $(G)$, the proximal $(X)$ and with distal $(D)$ convoluted tubules show normal structure. Mallory's, x400.

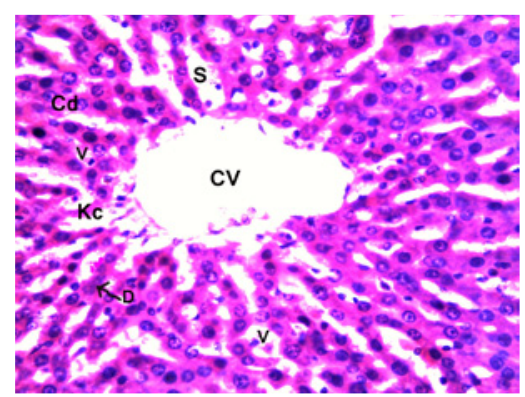

Figure 5: Light photomicrography of liver of a rat after eight weeks of exposure to $\mathrm{CdCl}$ 2. The trabecular structure of the liver is blurred. The hepatocyte cytoplasm is light, foamy and filled with vacuoles (V); cell sizes are enlarged, nuclear chromatin is more condensed $(\mathrm{Cd})$. Necrosis of single hepatocytes and the nuclei are contracted, pycnotic with condensed chromatin ( $D$ arrow), cytoplasm is strongly acidophilic. Accumulation of mononuclear cells in the vicinity of sinusoids (S). The sinusoid walls show numerous Kupffer cells (Kc). H\&E, $x 400$.

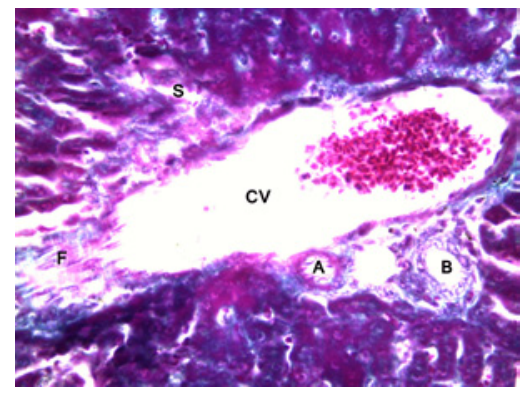

Figure 6: Light photomicrography of liver of a rat after eight weeks of exposure to $\mathrm{Cd} \mathrm{Cl2}$. Showing (i): tight cytoplasm, enlarged cell sizes. Condensed nuclear chromatin. Sinusoidal widening (S) with accumulation of mononuclear cells in its vicinity, (ii): portal fibrosis (F).N.B; Bile duct (B). Central vein (V) and hepatic artery (A). Mallory's x400.

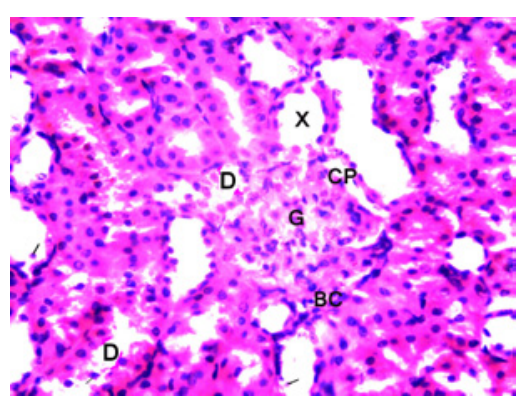

Figure 7: Light photomicrography of Kidney of rat after eight weeks of exposure to $\mathrm{Cd} \mathrm{Cl2}$, showing a vascular glomeruli $(\mathrm{G})$ are enlarged, tightly filling the glomerular capsular space (CP), with flat epithelium lining the Bowman's capsule (BC) Some cells of the proximal (X) and distal (D) convoluted tubular epithelium show features of oedema. Capillaries are filled with blood cells some tubules contain single desquamated cells (black lines). H\&E, x400.

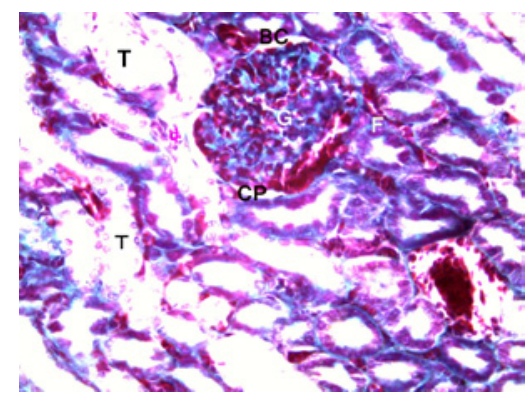

Figure 8: Light photomicrography of Kidney of rat after eight weeks of exposure to $\mathrm{Cd} \mathrm{Cl}$, illustrates tubular necrosis $(T)$ and fibrosis $(F)$, swelling renal glomeruli $(G)$ and decreases of the glomerular space $(C P)$ with some capsular fibrosis (BC). Mallory's .X $\mathbf{4 0 0 .}$

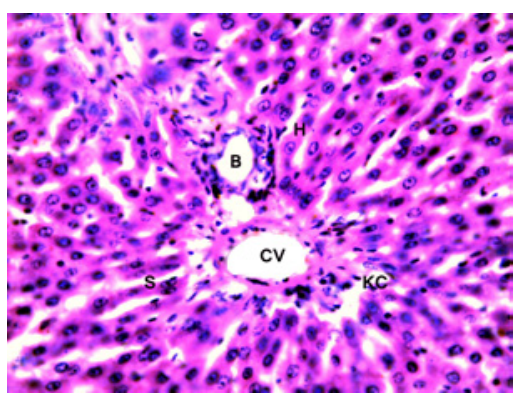

Figure 9: Light photomicrography of liver of rat after eight weeks of exposure to $\mathrm{Cd} \mathrm{Cl} 2$ and $\mathrm{Zncl} 2$. The liver organization appears normal with decreased widening of blood sinusoid (S), less fragmentation of hepatocytes nuclei ,less lighting of the cytoplasm and decrease the mononuclear cells infiltration in the vicinity ofporal system mainly around the central vein (CV) and bile duct(B). H\&E, $\mathbf{x 2 0 0 .}$

$\mathrm{ZnCl}_{2}$ in combination with $\mathrm{CdCl}_{2}$ caused an reduction of toxic effects of $\mathrm{CdCl}_{2}$ on the liver were an absence of nucleus fragmentation and a decrease in the sinusoidal dilation, necrosis of some hepatocytes, mononuclear cell infiltrations; was observed.. In fact we noticed the presence of rare inflammatory sites in the sinusoids and some hepatocytes with light cytoplasm (Figure 9 and 10).

Light microscopic examination also revealed a positive correlation between $\mathrm{ZnCl}_{2}$ and $\mathrm{CdCl}_{2}$ in the kidney tissues with marked reduction 
Citation: Mahran AA, Husam Eldien HO, Abd El-Mawla AMA, Attia AM (2011) Protective Effect of Zinc (Zn) on the Histology and Histochemistry of Liver and Kidney of Albino Rat Treated with Cadmium. J Cytol Histol 2:123. doi:10.4172/2157-7099.1000123

of the toxic effect on the kidney. However, some toxic effects of $\mathrm{CdCl}_{2}$, as mild hyperaemia in the kidney vessels, some degenerative changes in the tubular epithelium and cystic dilatation were observed (Figure 11 and 12).

\section{Histochemical observations}

The light microscopic observations revealed that, the liver and kidney tissues of the control group should positive PAS reaction in the cells cytoplasm, more in the liver (Figure 13) than in the kidney (Figure 14) with PAS positive reaction in the brush borders of the proximal

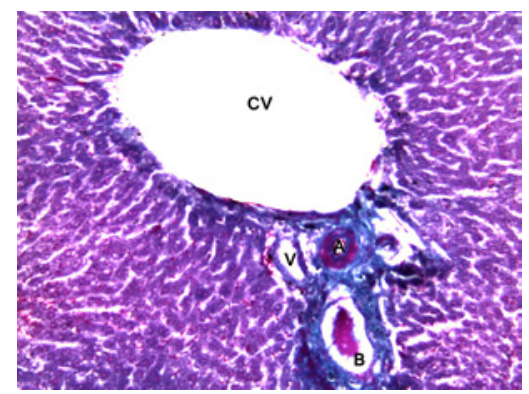

Figure 10: Light photomicrography of liver of rat after eight weeks of exposure to $\mathrm{Cd} \mathrm{Cl} 2$ and $\mathrm{Zncl} 2$,showing marked decreased in portal mononuclear cells infiltration around the central vei (CV), bile duct (B), hepatic artery $(A)$ and portal vein $(\mathrm{V})$, with normal organization of the liver tissues. Mallory's x200.

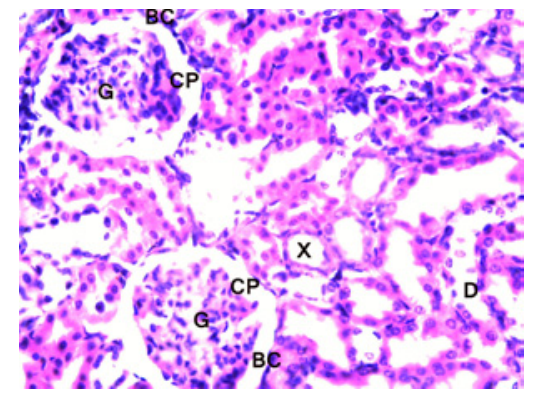

Figure 11: Light photomicrography of Kidney of rat after eight weeks of exposure to $\mathrm{Cd} \mathrm{Cl} 2$ and $\mathrm{ZnCl} 2$.showing an decreased in the vasculature of the renal glomeruli $(\mathrm{G})$,appearance of the glomerular capsular space (CP). Decrease the oedema of both the proximal (X), and distal (D) convoluted tubular epithelium. Lack of the fibroses in the Bowman's capsule (BC). H\&E, $\mathbf{x} 400$.

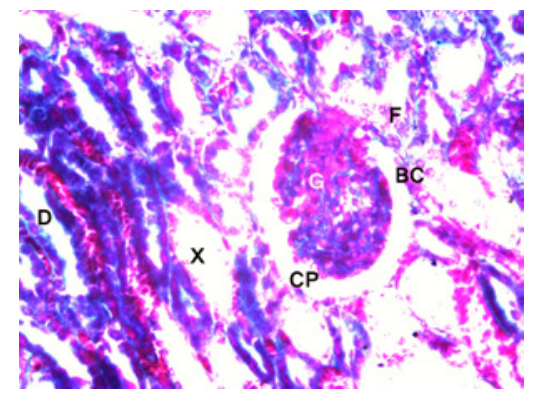

Figure 12: Light photomicrography of Kidney of rat after eight weeks of exposure to $\mathrm{Cd} \mathrm{Cl} 2$ and $\mathrm{ZnCl} 2$.showing an decreased in necrosis as well as tissues fibrosis $(F)$ in renal glomeruli $(G)$,Bowman's capsule (BC), Proximal $(X)$ and distal (D) convoluted tubules. Also there is an decrease swelling of glomeruli and appearance of the capsular space (CP). Mallory's .X 400.

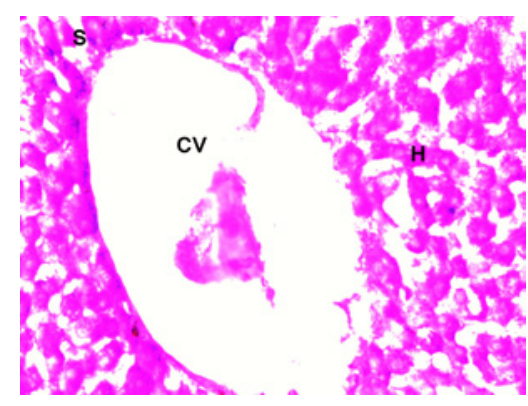

Figure 13: Light photomicrography of liver of a control rat, showing a positive reaction of PAS in all its components particularly the hepatocytes $(H)$. N.B; Bile duct (B). Hepatic artery (A), and blood sinusoid (S). Periodic acid-Schiff's $X$ 400.

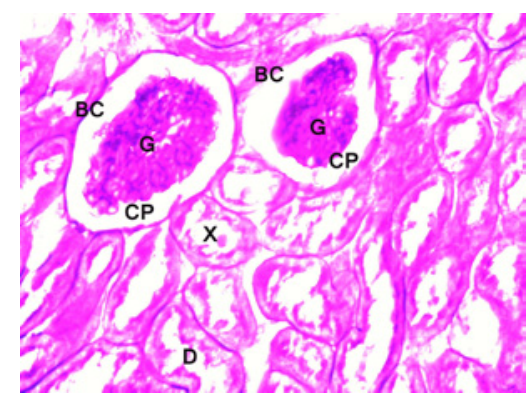

Figure 14: Light photomicrography of Kidney (cortical part) of a control rat. The strong positive reaction of PAS in renal glomeruli $(G)$, flat epithelium lining the glomerular capsule $(B C)$ with distinct capsular space $(C P)$, the proximal $(X)$ and with distal (D) convoluted tubules can be seen. Periodic acid-Schiff's $\mathrm{X} 400$.

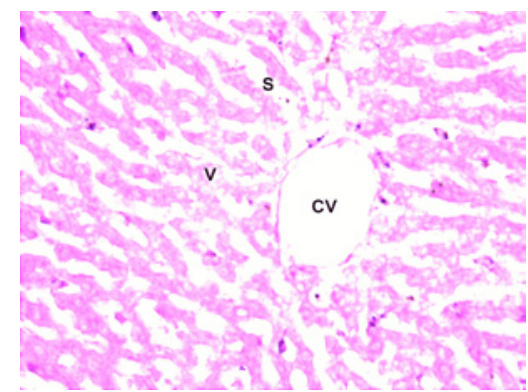

Figure 15: Light photomicrography of liver of rat after eight weeks of exposure to $\mathrm{Cd} \mathrm{Cl2}$, showing a marked decrease in PAS reaction in all vicinity of the liver particularly the hepatocytes . N.B. Central vein (CV). Vacuoles (V) and blood sinusoid (S). Periodic acid-Schiff's X $\mathbf{4 0 0}$.

convoluted tubules. While the glomeruli were intensely positive to PAS reaction.

The Liver and kidney tissues of the rats exposed to $\mathrm{CdCl}_{2}$ alone should, a marked reduction in PAS reaction in both liver (Figure 15) and kidney (Figure 16) tissues particularly in degenerative and necrotic areas. The kidney tissue appeared more affected than the liver. The reduction in PAS reaction was more intensive in the renal tubules and glomeruli.

The PAS reaction of both liver and kidney tissues of the rats exposed to $\mathrm{CdCl}_{2}$ in combination with $\mathrm{ZnCl}_{2}$ for eight weeks appeared 
Citation: Mahran AA, Husam Eldien HO, Abd El-Mawla AMA, Attia AM (2011) Protective Effect of Zinc (Zn) on the Histology and Histochemistry of Liver and Kidney of Albino Rat Treated with Cadmium. J Cytol Histol 2:123. doi:10.4172/2157-7099.1000123

Page 5 of 9

to have a moderate increased in intensity of PAS positive reaction in the liver (Figure 17) and kidney (Figure 18) tissues but not reach to the normal level.

\section{Transmission electronmicroscopic observations}

The Liver of a control rat showed that a normal ultrastructure; the cytoplasm of hepatocytes appeared to have a fine granular appearance due the presence of numerous free glycogen granules. The nuclei of the hepatocytes were oval or rounded and the nucleoplasm showed a fine granular component with a thin peripheral heterochromatin and euchromatin condensation. The mitochondria were numerous, usually round to oval in shape. The blood sinusoids appeared to be lined by

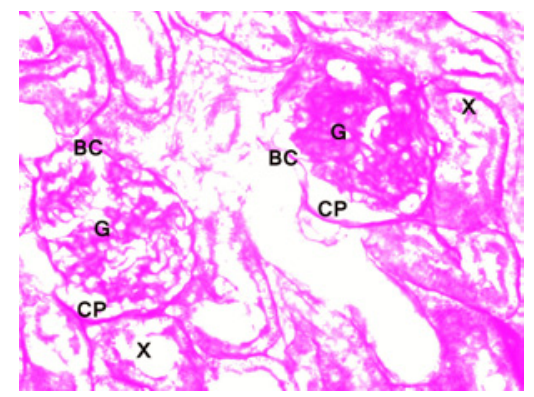

Figure 16: Light photomicrography of Kidney of rat after eight weeks of exposure to $\mathrm{Cd} \mathrm{Cl}$, showing an decreased in the PAS positive reaction of renal glomeruli (G),Bowman's capsule (BC), and proximal convoluted tubules (X). Periodic acid-Schiff's X 400.

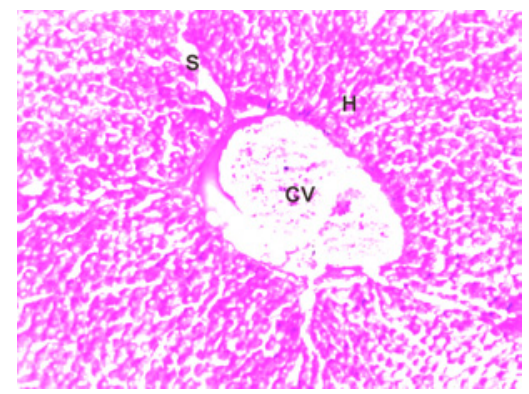

Figure 17: Light photomicrography of liver of rat after eight weeks of exposure to $\mathrm{Cd} \mathrm{Cl} 2$ and $\mathrm{Zncl} 2$, showing marked increased in PAS reactions in different of the liver .N.B; Central vein (CV). Hepatocytes (H).Blood sinusoid (S). Periodic acid-Schiff's X 200.

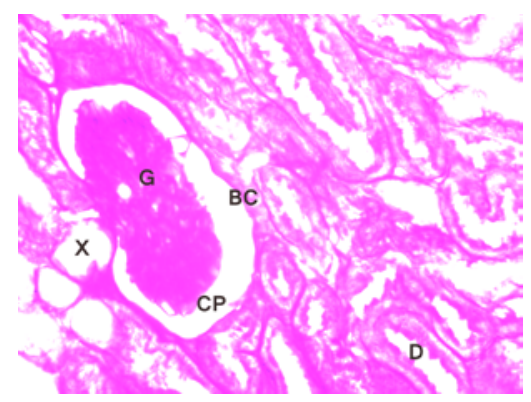

Figure 18: Light photomicrography of Kidney of rat after eight weeks of exposure to $\mathrm{Cd} \mathrm{Cl} 2$ and $\mathrm{ZnCl} 2$.Marked increase in PAS positive reaction in renal glomeruli $(\mathrm{G})$,Bowman's capsule $(\mathrm{BC})$, and both proximal $(\mathrm{X})$ and distal (D)convoluted tubules. Periodic acid-Schiff's X 400.

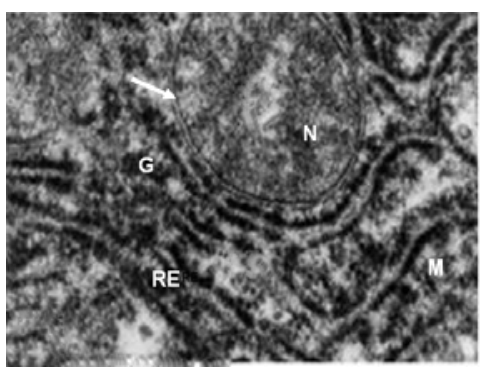

Figure 19: Transmission electron microscopic picture of a section of liver of control rat showing, a normal hepatocyte with euchromatic nucleus (N) ,prominent nuclear membrane (white arrow), Golgi apparatus (G),rough endoplasmic reticulum (RE) and many mitochondria (M) having normal crestae. TEM mag. $=8000 \mathrm{X}$

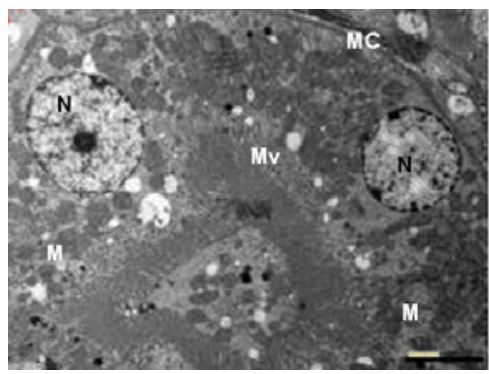

Figure 20: Transmission electron microscopic picture of a section of kidney of control rat showing, the cells of the proximal convoluted tubule with euchromatic nuclei(N) and prominent nucleolus (n),many mitochondria (M) having normal crestae. The brush border of the cells has normal microvilli (Mv), and the basal lamina $(\mathrm{CM})$ appears normal. TEM mag. $=6000 \mathrm{X}$.

flat endothelial cells or their extensions which were separated from the adjacent hepatocytes by the subendothelial space or space of Disse (Figure 19).

Transmission electron microscopic observations of kidney of the control rats showed the endothelial cells in the glomerular capillaries were very richly fenestrated with large pores which appeared to lack any trace of a closing diaphragm. The proximal renal tubular epithelium of control rat is characterized by a dense brush border, basal or central nucleus, apical endocytic vesicles, occasional lysosomes and elongate or round mitochondria. Cisternal profiles of rough ER located between the mitochondria (Figure 20)

In the experimental group 1 which exposed to $\mathrm{CdCl}_{2}$ alone the transmission electron microscopic observation of the liver tissue revealed a histopathological changed in the hepatocytes, which appeared as thickening and enfolding of the cell membrane, damage of the nuclear membrane ,regression of mitochondrial cisternae, deterioration of rough endoplasmic retinacula, losses of glycogen particles, and proliferation of smooth endoplasmic reticula with condensation of the nuclear chromatins. The hepatocytes also appeared to be contains many cytoplasmic fat droplets and many vacuoles (Figure 21). The blood sinusoid appeared to be more dilated with many Kupffer cells seen in contact with its endothelial lining. The hepatocytes appeare to be contains many cytoplasmic fat droplets and many vacuoles (Figure 21).

The $\mathrm{CdCl}_{2}$ induced a toxic ultrastructural changed in the kidney which observed as, enlargement of the glumeruli with narrowing of 
Citation: Mahran AA, Husam Eldien HO, Abd El-Mawla AMA, Attia AM (2011) Protective Effect of Zinc (Zn) on the Histology and Histochemistry of Liver and Kidney of Albino Rat Treated with Cadmium. J Cytol Histol 2:123. doi:10.4172/2157-7099.1000123

the capillary lumen, swelling of the capillary endothelium, and loss of the fenesrtae. damage of the renal tubules s were noted as focal loss of the brush border of the epithelial lining of proximal renal tubules ,disturbance of the nuclear membrane, chromatin condensation, swelling of several mitochondria with regression of their crestae. The protein synthesis rough endoplasmic reticulum was degenerated. Increased number of lysosomes and cell death were also noticed (Figure 22 and 23).

Rats of experimental group 2 which exposed to $\mathrm{CdCl}_{2}$ in combination with $\mathrm{ZnCl}_{2}$; in this group, co-administration of $\mathrm{ZnCl}_{2}$ practically prevented most of the ultrastructural pathological toxic effects of $\mathrm{CdCl}_{2}$ on the liver tissues. In fact we observed the presence of rare sites of ultrastructural pathological changes in the blood sinusoids and hepatocytes (Figure 24). In the kidney, many of ultrastructural pathological changes caused by the toxic effect of $\mathrm{CdCl}_{2}$ on the kidney tissues were noticed to be decreased in the kidney tissues of rats received $\mathrm{ZnCl}_{2}$ in combination with $\mathrm{CdCl}_{2}$ for eight weeks (Figure 25).

\section{Discussion}

Cd is used worldwide in modern industries. Therefore, Cd pollution was internationally recognized as the most important environmental health hazard that remains to be eliminated [17]. When Cd is taken into the human body through the oral route by the ingestion of

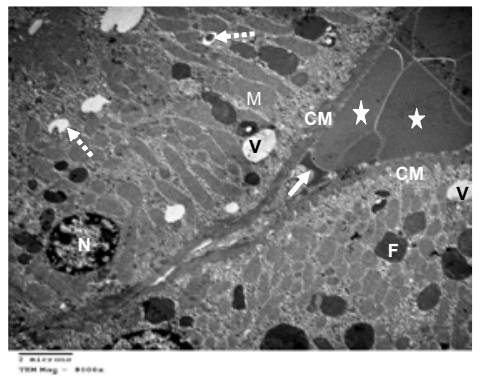

Figure 21: Ultramıcrograph ot a section ot IIver ot rat exposed to $\mathrm{Cd} \mathrm{Cl} 2$ for 8 weeks, showing two liver cells with heterochromatic nuclei $(\mathrm{N})$, numerous elongated mitochondria (M).Some lipid droplets $(F)$,many lysosomes (broken arrows)as well as many vacuoles (V) appeared in cells cytoplasm,. A blood sinusoid (arrow) contains RPCs $\left(^{*}\right.$ ) is seen in between. The basal lamina appeared thick and infolded (CM). TEM mag. $=8000 \mathrm{X}$.

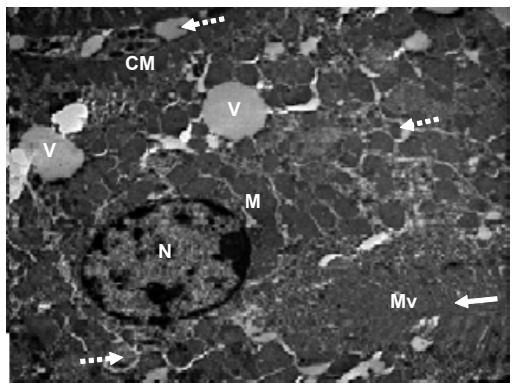

Figure 22: Ultramicrograph of a section of kidney of rat exposed to $\mathrm{Cd}$ $\mathrm{Cl} 2$ for 8 weeks, showing cell of proximal convoluted tubule with rounded heterochromatic nucleus $(\mathrm{N})$, basal elongated mitochondria $(\mathrm{M})$, and thick enfolded cell membrane (CM) .disorganized apical microvilli (Mc) around the tubular lumen (arrow). The protoplasm appeared to be contains numerous vacuoles $(\mathrm{V})$ and lysosomes (broken arrows). TEM mag. $=8000 \mathrm{X}$

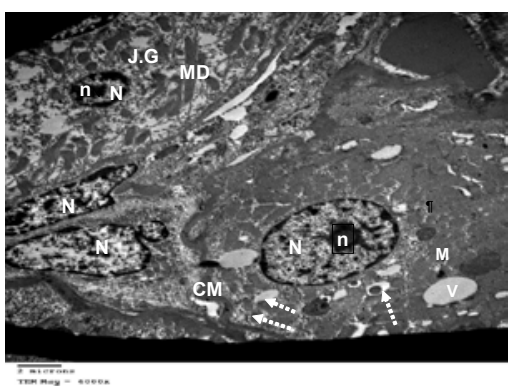

Figure 23: Ultramicrograph of a section through joxtaglomerular complex of kidney of rat exposed to $\mathrm{Cd} \mathrm{Cl} 2$ for 8 weeks, showing (1) Macula densa $(\mathrm{Md})$ with elongated nucleus $(\mathrm{N})$, prominent nucleoli( $\mathrm{n}$ )and cytoplasm contains many mitochondria(M), vacuoles (V)and lysosomes (broken arrows). (2) Joxtaglomerular cell (J.G) has rounded heterochromatic nucleus $(\mathrm{N})$, nucleolus $(\mathrm{n})$, many mitochondria(M), and pale ,vacuolated (V)protoplasm. The basal lamina (CM) of the seen cells is thick and enfolded. TEM mag. $=6000 \mathrm{X}$.

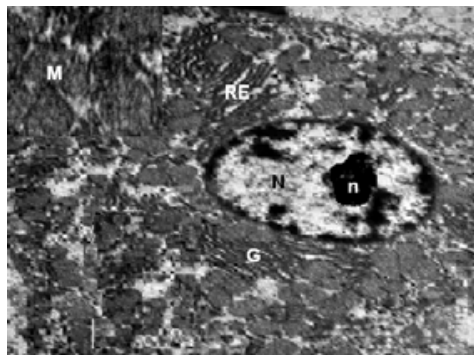

Figure 24: Transmission electron microscopic picture of a section of live of rat exposed to $\mathrm{Cd} \mathrm{Cl} 2$ and $\mathrm{ZnCl} 2$ for 8 weeks, showing, hepatocyte with euchromatic nucleus $(\mathrm{N})$ and prominent nucleolus $(\mathrm{n})$. Golgi apparatus $(\mathrm{G})$ and rough endoplasmic reticulum (RE), numerous mitochondria are seen in less vacuolated protoplasm. TEM $\mathbf{m a g} .=8000 \mathrm{X}$.

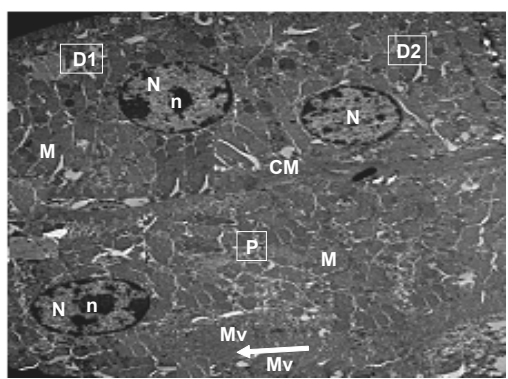

Figure 25: Transmission electron microscopic picture of a section of kidney of rat exposed to $\mathrm{Cd} \mathrm{Cl}$ and $\mathrm{ZnCl} 2$ for 8 weeks displays two cells of distal convoluted tubules (D1\&D2) and one cell of proximal convoluted tubules $(P)$ with euchromatic nuclei $(\mathrm{N})$ and nucleolus ( $\mathrm{n}$ ),many mitochondria (M)and dark nonvacuolated protoplasm. Intact microvilli (Mv) surrounded the lumen (arrow) of the proximal convoluted tubule. TEM mag. $=4000 \mathrm{X}$.

contaminated water or food, it accumulates in the liver and kidneys and its half-life is very long, exceeding $10 \mathrm{yr}[10,18]$.

Once $\mathrm{Cd}$ is absorbed into the liver from the digestive tract, it stimulates the synthesis of metallothionin (MT) in the organs and the forms MT bound Cd (MT-Cd). The MT-Cd transfers to the kidneys via the blood stream. When MTCd reaches the kidney, it is filtered through the glomerular membrane and is reabsorbed in the proximal tubular cells. MT-Cd shows strong nephrotoxicity after pinocytosis and accumulation in the proximal tubular cells [19]. 
Citation: Mahran AA, Husam Eldien HO, Abd El-Mawla AMA, Attia AM (2011) Protective Effect of Zinc (Zn) on the Histology and Histochemistry of Liver and Kidney of Albino Rat Treated with Cadmium. J Cytol Histol 2:123. doi:10.4172/2157-7099.1000123

In agreement with a large number of studies who noted similar or more pronounced changes in the hepatic and renal tissues under Cd effect $[2,9,11,20-24]$. Our results indicated significant $\mathrm{CdCl}_{2}$ toxic effects on the liver and kidney structures. As mentioned previously [20] early pathological changes in rat kidney obtained after 6 weeks of administration of $50 \mathrm{mg} \mathrm{Cd} / \mathrm{l}$ in drinking water. After 12 weeks, they revealed signs of tubular necrosis, interstitial fibrosis and glomerular epithelial cell hypertrophy in small areas of the kidney cortex. In fact, it has been suggested that Cd disturbs membranes integrity $[25,26]$ generates reactive oxygen species [22,27] and involves cytotoxic and inflammatory mediators $[28,29]$ in the liver and kidney.

In agreement with a large number studies [11,24,30-33], our results indicated a significant ultastructural damages in $\mathrm{CdCl}_{2}$ contaminated liver, which observed mainly in hepatocytes as chromatin condensation, swelling of mitochondria with regression of mitochondrial cristea, disintegration of protein synthesis structures such as rough endoplasmic reticulum and increased number of lysosmes and ultimately cell death. Also the hepatcytes cytoplasm showed some intra cellular vacuoles and reduced glycogen granules. These were evident in all animals of the Cd-contaminated group. Similar or more advanced changes in the liver and kidney structures under $\mathrm{CdCl}_{2}$ influence have been reported by others [11,24,30-35] who suggested that $\mathrm{Cd}$ inhibits protein synthesis and glycogen metabolism in the liver. Also reported data [36] postulated that, cell membranes were disintegrated and manifested by the occurrence of vacuoles in the cytoplasm, and in some cells the changes were lees evident and dense mitochondria with distinct membranes were found.

In the present study, some pathological changes in kidney ultrastructure as narrowing of the capillary lumen and swelling of the capillary endothelium of the glomeruli, injured brush-border microvilli and swollen mitochondria in the proximal convoluted tubular cells were observed. These results were in agreement with that of $[11,22,23,37]$.

The narrowing of capillary lumina contributes to the hypertension reported previously [38] in rats following cadmium intoxication. Hypertension may result from cadmium-induced changes in vasculature, the rennin-angiotensin system, or renal ion transport process. The initial effect of cadmium administration is on the integrity and permeability of the vascular endothelium; other necrotic changes occur secondary to this effect have been declared [39].

In the present study, the effects of cadmium on proximal cell ultrastructure were, focal loss of brush border, nuclear membrane damage, chromatin condensation, swelling of the mitochondria with regression of mitochondrial crestae, degranulation and disintegration of protein-synthesizing structures such as rough endoplasmic reticulum, increased number of lysosomes and ultimately cell death. These changes were attributed to the reduction of the surface density of microvillus membrane per unit cell volume to $19 \%$ in cadmium contaminated rats $[15,40]$. Cadmium also inhibits the vacuolar $\mathrm{H}^{*}$ ATPase and endocytosis in proximal tubule brush border of rat kidney and this may inhibit endocytosis of filtered proteins and impair vesiclemediated recycling of some membrane [41].

The mitochondrial swelling and degeneration of the mitochondria cristae observed in our study may reflect the disturbances in oxyreduction processes taking place in the organelle [42]. Also, the changes in the nucleus, such as chromatin condensation indicate that this organelle is affected in a major way from cadmium exposure.
Chromatin condensation suggests progressive inactivation of the nuclear component, probably due to inhibition of DNA repair and DNA methylation $[43,44]$. Furthermore, proliferation in the number of lysosomes in cells of the proximal tubules is typical of heavy metal exposure. It has been suggested that this alteration may represent a cellular response to heavy metals such as cadmium. The increased number of lysosomes, a result of the attempt to digest these heavy metals or toxic substances, is considered a general manifestation of injury. The sequestration of damaged organelles in lysosomes is a mechanism of cellular repair and follows all types of sublethal injury [45].

In $\mathrm{Zn}$ co-treated animals, we noticed an improvement in the $\mathrm{Cd}$-induced damage in the liver. Our results were in agreement with published data [46] which reported that the effect of co-treatment with Zn during Cd administration completely prevented the changes in renal function produced by the toxic metal in the rat, even though they did not find any significant difference in the renal Cd content. There is considerable information in the literature regarding the protective effect of $\mathrm{Zn}$ against the cellular toxicity caused by Cd. Previous studies [47-50] supposed that $\mathrm{Zn}$ protection is perhaps due to redistribution of $\mathrm{Cd}$ in the organism since $\mathrm{Zn}$ is able to induce synthesis of metalothionin in the liver and kidneys. However, another hypothesis must be proposed to explain the protective effect of $\mathrm{Zn}$ which appeared through our histological. Findings in spite of the further accumulation of $\mathrm{Cd}$ in the liver and kidney. In fact, in recent studies, $\mathrm{Zn}$ has been demonstrated to play an important rule in preventing the oxidative stress, apoptosis and necrosis induced by Cd [9,51-53].

In the present study there is considerable improvement in $\mathrm{Cd}$ induced toxic damages on both liver and kidney tissues in $\mathrm{Zn}$ supplementation with $\mathrm{Cd}$ for 8 weeks. Our results were in agreement with those previously reported $[9,24,46,51,53]$ which postulated that, $\mathrm{Zn}$ play an important rule in preventing the oxidative stress, apoptosis and the necrosis induced by Cd. Moreover, in a plant study. Zn and Se have been shown to have similar characteristics in their antagonism against $\mathrm{Cd}$. Soil enrichment with the two trace elements was helpful in antagonizing $\mathrm{Cd}$ absorption by plant roots [54]. In contrast to the present findings, it has been reported that, no significant effect of $\mathrm{Zn}$ on Cd toxicity of liver and kidney tissues, and they attributed this lack of positive effect of $\mathrm{Zn}$ to the lack of time for metalothionien synthesis caused by administration of $\mathrm{Zn}$ and $\mathrm{Cd}$ simultaneously [2].

\section{Conclusion}

Our results demonstrate the ameliorative effect of $\mathrm{Zn}$ supply on the $\mathrm{Cd}$ induced toxic structural changes in the liver and kidney tissues of the rats. These results validate the hypothesis that the metabolism and toxic action of $\mathrm{Cd}$ may be modulated by $\mathrm{Zn}$ supplementation.

\section{References}

1. Schrey P, Wittsiepe J, Budde U, Heinzow B, Idel H, et al. (2000) Dietary intake of lead, cadmium, copper and zinc by children from the German North Sea island Amrum. Int J Hyg Environ Health 203: 1-9.

2. Uyanik F, Eren M, Atasever A, TunD oku G, Kolsuz HA (2001) Changes in some biochemical parameters and organs of broilers exposed to cadmium and effect of zinc on cadmium induced alterations. Isra J of Vet Med 56: 128-134.

3. Gupta P, Neera S (2006) Effects of sub-lethal concentrations of zinc on histological changes and bioaccumulation of zinc by kidney of fish, Channa punctatus (Bloch). J Environ Biol 27: 211-215.

4. Agtas S, Gey H, Gul S (2007) Concentrations of heavy metals in water and chub, Leuciscus cephalus (Linn.) from the river Yildiz, Turkey. J Environ Biol 28: 845-849. 
Citation: Mahran AA, Husam Eldien HO, Abd El-Mawla AMA, Attia AM (2011) Protective Effect of Zinc (Zn) on the Histology and Histochemistry of Liver and Kidney of Albino Rat Treated with Cadmium. J Cytol Histol 2:123. doi:10.4172/2157-7099.1000123

5. Yoon S, Han SS, Rana SV (2008) Molecular markers of heavy metal toxicity - A new paradigm for health risk assessment. J Environ Biol 29: 1-14.

6. McDowell LR (1992) Minerals in Animal and Human Nutrition, Academic Press, New York, 359-361.

7. Yannai S, Sachs KM (1993) Absorption and accumulation of cadmium, lead and mercury from foods by rats. Food Chem Toxicol 31: 351-355.

8. Khandelwal S, Agnihotri N, Tandon SK (1991) Biochemical response to cadmium: dose-time effect. Biol Trace Elem Res 29: 157-164.

9. Smalinskienel A, Lesauskaitel V, RyselisI S, Abdrakhmanov O, Kregzdyte R, et al. (2006) Effects of six-week intoxication on cadmium and zinc distribution in internal organs and blood and on the mitotic activity of liver cells. Biologija 1: $76-79$.

10. Teranishi H, Takagawa K, Aral Y, Wakaki KS, Takaya K (2002) Histologica Staining of Cadmium with 2-(8-quinolylazo)-4,5-diphenylimidazole (QAI) in the Kidneys of Rats Periorally Exposed to Cadmium. J Occup Health 44: 60-62.

11. Brzóska MM, Moniuszko-Jakoniuk J, Piłat-Marcinkiewicz B, Sawicki B (2003) Liver and kidney function and histology in rats exposed to cadmium and ethanol. Alcohol Alcohol 38: 2-10.

12. Liu J, Squibb KS, Akkerman M, Nordberg GF, Lipsky M, et al. (1996) Cytotoxicity, zinc protection, and stress protein induction in rat proximal tubule cells exposed to cadmium chloride in primary cell culture. Ren Fail 18: 867-882.

13. Barbier O, Jacquillet G, Tauc M, Poujeol P, Cougnon M (2004) Acute study of interaction between cadmium, calcium and zinc transport along the rat nephron in vivo. Am J Physiol Renal Physiol 287: F1067-1075.

14. Bancroft JD, Gamble M (2002) Theory and Practice Histological Techniques, $5^{\text {th }}$ ed., Churchill Livingstone. New York, Edinburgh and London, 126: 173-175.

15. Hotchkiss RD (1948) Microchemical reaction resulting in the staining of polysaccharide structures in fixed tissue preparations. Arch Biochem 16: 131141

16. WATSON ML (1958) Staining of tissue sections for electron microscopy with heavy metals. J Biophys Biochem Cytol 4: 475-478.

17. Nogawa K, Kurach M, Kasuya M (1999) Advances in the prevention of environmental cadmium pollution and countermeasures. Kanazawa: Eiko Laboratory.

18. Kramarova M, Massanyi P, Jancova A, Toman R, Slamecka J, et al. (2005) Concentration of cadmium in the liver and kidneys of some wild and farm animals. Bull Vet Inst Pulawy 49: 465-469.

19. Nordberg M (1984) General aspects of cadmium:transport, uptake and metabolism by the kidney. Environ Health Perspect 54: 13-20.

20. Aughey E, Fell GS, Scott R, Black M (1984) Histopathology of early effects of oral cadmium in the rat kidney. Environ health perspect 54: 153-161.

21. Xiao P, Jia XD, Zhong WJ, Jin XP, Nordberg G (2002) Restorative effects of zinc and selenium on cadmium-induced kidney oxidative damage in rats. Biomed Environ Sci 15: 67-74.

22. Koyu A, Gokcimen A, Ozguner F, Bayram DS, Kocak A (2006) Evaluation of the effects of cadmium on rat liver. Mol Cell Biochem 284: 81-85.

23. Nakazato K, Nagamine T, Suzuki K, Kusakabe T, Moon HD, et al. (2007) Subcellular changes of essential metal shown by in-air micro-PIXE in oral cadmium-exposed mice. Biometals 21: 83-91.

24. Jihen $E H$, Imed M, Fatema $H$, Abdelhamid K (2008) Protective effects of selenium (Se) and zinc ( $\mathrm{Zn}$ ) on cadmium (Cd) toxicity in the liver and kidney of the rat: Histology and Cd accumulation. Food Chem Toxicol 46: 3522-3527.

25. Muller L (1986) Consequences of cadmium toxicity in rat hepatocytes: Mitochondrial dysfunction and lipid peroxidation. Toxicology 40: 285-295.

26. Nordberg GF, Jin T, Nordberg M (1994) Subcellular targets of cadmium nephrotoxicity: cadmium binding to renal membrane proteins in animals with or without protective metallothionein synthesis. Environ Health Perspect 102: 191-194.

27. El-Sharaky AS, Newairy AA, Badreldeen MM, Eweda SM, Sheweita SA (2007) Protective role of selenium against renal toxicity induced by cadmium in rats. Toxicol 235: 185-193.
28. Kayama F, Yoshida T, Elwell MR, Luster MI (1995) Cadmium-induced rena damage and proinflammatory cytokines: possible role of IL-6 in tubular epithelial cell regeneration. Toxicol Appl Pharmacol 134: 23-34.

29. Rikans LE, Yamano $T$ (2000) Mechanisms of cadmium-mediated acute hepatotoxicity. J Biochem Mol Toxicol 14: 110-117.

30. Brzoska MM, Moniuszko-Jakoniuk J, Jurczuk M, Galazyn-Sidorczuk M Rogalska J (2000) Effect of short-term ethanol administration on cadmium retention and bioelements metabolism in rats continuously exposed to cadmium. Alcohol Alcohol 35: 439-445.

31. Brzoska MM, Moniuszko-Jakoniuk J, Jurczuk M, Galazyn-Sidorczuk M (2002) Cadmium turnover and changes of zinc and copper bodystatus of rats continuously exposed to cadmium and ethanol. Alcohol Alcohol 37: 213-221.

32. Mitsumori K, Shibutani M, Sato S, Onodera H, Nakagawa J, et al. (1998) Relationship between the development of hepato-renal toxicity and cadmium accumulation in rats given minimum to large amounts of cadmium chloride in the long-term: preliminary study. Archi Toxicol 72: 545-552.

33. Czykier E, Szynaka B, Moniuszko-Jakoniuk J, Sawicki B (2002) Ultrastructura and enzymatic studies of rat liver after acute cadmium exposure. Rocz Akad Med Bialymst 47: 203-212.

34. Nakamura K, Nishiyama S, Takata T, ,Suzuki E, Sugiura Y, et al. (1981) The effects of zinc on cadmium-induced ultrastructural changes in rat livers Sangyo Igaku 23: 141-145.

35. Dudley RE, Gammal LM, Klaassen CD (1985) Cadmium-induced hepatic and renal injury in chronically exposed rats: likely role of hepatic cadmiummetallothionein in nephrotoxicity. Toxicol Appl Pharmacol 77: 414-426.

36. Massanyi P, Uhrin V, Sirotkin AV, Paksy K, Forgacs ZS, et al. (2000) Effects of cadmium on ultra structure and steroid genesis in cultured porcine ovarian granulose cells. Acta Vet Brno 69: 101-106.

37. Abdel-Monein AM, Said KM (2007) Acute effect of cadmium treatment on the kidney of rats; biochemical and ultrastructrual studies. Pak J of Biol Sci 10 3496-3506.

38. Puri VN, Saha S (2003) Comparison of acute cardiovascular effects of cadmium and captopril in relation to oxidant and angiotensin converting enzyme activity in rats. Drug Chem Toxicol 26: 213-218.

39. Nolan CV, Shaikh ZA (1986) The vascular endothelium as a target tissue in acute cadmium toxicity. Life Sci 39: 1403-1409.

40. Condron RJ, Schroen CJ, Marshall AT (1994) Morphometric analysis of renal proximal tubules in cadmium-treated rats. J Submicrosc Cyto Pathol 26: 51-58.

41. Herak-Kramberger CM, Brown D, Sabolic I (1998) Cadmium inhibits vacuola $\mathrm{H}^{+}$-ATPase and endocytosis in rat kidney cortex. Kidney Int 53: 1713-1726.

42. Thevenod F (2003) Nephrotoxiciry and the proximal tubule. Insights from cadmium. Nephron Physiol 93: 87-93.

43. Colegio OR, Van Itallie C, Rahner C, Anderson JM (2003) Claudin extracellular domains determine paracellular charge selectivity and resistance but not tight junction fibril architecture. Am J Physiol Cell Physiol 284: C1346-C1354

44. Waisberg MP, Joseph B, Hale B, Beyersmann D (2003) Molecular and cellular mechanisms of cadmium carcinogenesis. Toxicology 192: 95-117.

45. Cheville NF (1994) Ultrastructural Pathology: An Introduction to Interpretation. 1st Edn, Ames, lowa: lowa State Univer. Press 67-68.

46. Jacquillet G, Barbier O, Cougnon M, Tauc M, Namorado MC, et al. (2006) Zinc protects renal function during cadmium intoxication in the rat. Am J Physio Renal Physiol 290: F127-137.

47. Bonner FW, King LJ, Parke DV (1981) The influence of high dietary zinc on tissue disposition and urinary excretion of cadmium, zinc, copper and iron after repeated parenteral administration of cadmium to rats. Toxicology 19: 247- 254

48. Lamphere DN, Dorn CR, Reddy CS, Meyer AW (1984) Reduced cadmium body burden in cadmium-exposed calves fed supplemental zinc. Environ. Res 33: $119-129$

49. Olsson M, Jonsson S, Oskarsson A (2001) Cadmium and zinc in kidney, liver muscle and mammary tissue from dairy cows in conventional and organic farming. J Environ Monit 3: 531-538. 
Citation: Mahran AA, Husam Eldien HO, Abd El-Mawla AMA, Attia AM (2011) Protective Effect of Zinc (Zn) on the Histology and Histochemistry of Liver and Kidney of Albino Rat Treated with Cadmium. J Cytol Histol 2:123. doi:10.4172/2157-7099.1000123

Page 9 of 9

50. Ueda F, Seki H, Fujiwara H, Ebara K, Minomiya S et al. (1987) Interacting effects of zinc and cadmium on the cadmium distribution in the mouse. Ve Hum Toxicol 29: 367-372.

51. Rostan EF, DeBuys HV, Madey DL, Pinnell SR (2002) Evidence supporting zinc as an important antioxidant for skin. Int J Dermatol 41: 606-611.

52. Smalinskienel A, Gaileviciute R, Lesauskaite V, Sadauskiene I, Abdrakhmanov
O, et al. (2005) Effects of cadmium and zinc ions on mitotic activity and protein synthesis in mouse liver. Medicina (Kaunas) 41: 506-511.

53. Jemai H, Messaoudi I, Chaouch A, Kerkeni A (2007) Protective effect of zinc supplementation on blood antioxidant defense system in rats exposed to cadmium. J Trace Elem Med Biol 21: 269-273.

54. Hu H (2000) Exposure to metals. Prim Care 27: 983-996 